\title{
Understanding the impact of confessional diversity in the Lebanese public sector. Case study: The Lebanese Ministry of Finance
}

\author{
Fadi Bou Reslan ${ }^{1}$ (D \\ Accepted: 27 January 2022 \\ (c) The Author(s), under exclusive licence to Springer Science+Business Media, LLC, part of Springer Nature 2022
}

\begin{abstract}
The large size and function of the Lebanese civil service emphasize the significant value of civil service performance and equal employment opportunities. Generally, it is hard to attest to discrimination in recruitment because it is hidden in informal practices. Also, the selection process and the probable discrimination incident usually differ from one job seeker to another. This study investigates and analyzes the impact of confessional diversity on recruitment and selection, affective commitment, and career satisfaction in the Lebanese Ministry of Finance, where 195 questionnaires were distributed to different department employees. The proposed model is analyzed with partial least squares (PLS) path modeling in Smart PLS 3.0 software.
\end{abstract}

Keywords Confessional diversity $\cdot$ Recruitment and selection $\cdot$ Affective commitment Career satisfaction $\cdot$ Lebanese public sector

\section{Introduction}

The workplace is generally formed by a complex web of interactions among employees from diverse cultures and backgrounds. Workgroup diversity, with its disadvantages, can be an issue for an organization. However, it could also be suitable for businesses (Thomas \& Ely, 1996; Ilgen et al., 2005). Esty et al. (1995) defined diversity as identifying, comprehending, accepting, and appreciating people's differences concerning age, education, gender, race, ethnicity, disabilities, sexual orientation, and spiritual practice.

Diversity exists within various religious, ideological, and philosophical schools of thought or varying social classes, among other discriminatory characteristics. The meaning of diversity varies across societies (Hofstede, 2007). The United States is concerned with the racial combination (Griffin et al., 2016). In Britain, the ethno cultural system of a minority is essentially coterminous with the study of immigrants and their descendants (Li \& Heath, 2016). The discourse of diversity employed among German and French people is related to cultural discrepancies and international diversity rather than gender and ethnicity (Koopmans \&

Fadi Bou Reslan

fboureslan@gmail.com

1 Cyprus International University, Lefkosa, Mersin 10, Turkey
Schaeffer, 2016). As for the Lebanese society, diversity is commonly defined based on religion to one of the eighteen officially recognized sectarian groups (Badaan et al., 2020).

Religious diversity is the expression of belonging to a specific religious group or sect (Morgan, 2004), which could cause in-group favoritism or inequality between people (Cantone \& Wiener, 2017). Religious diversity can be identified by traditional dress, appearance, working hours and prayer breaks per day, celebrating religious holidays, or planning activities (Hambler, 2015). People of diverse religious might be prone to get into conflict (Nai et al., 2018). Religious diversity in Lebanon is usually indicated by the term "confessional diversity" or "confessionalism." This diversity distributes and secures equitable sharing of institutional, political, economic, and social power among various religious communities. Until this day, confessional diversity, as power-sharing between different religious groups (majorities and minorities) that constitute a separate and cohesive entity within the region in which the groups live, poses an insecure balance (Hanf, 2015).

Religious discrimination is expanding faster than other types of discrimination as to gender or race (Beyer \& Beaman, 2019). A limited number of publications are aware of confessional diversity and/or religious discrimination within organizations. Some previous studies have shown that organizations that engage people in their workforce from different cultural backgrounds and openly encourage them to express 
their religious beliefs at the office are likely to become more successful. This might improve their productivity, increase their integrity, motivation, and job satisfaction (Cavanagh \& Bandsuch, 2002), relieve their physical and psychological symptom of stress (Koenig, 1995), and enhance the organizational performance (Jurkiewicz \& Giacalone, 2004; Van Knippenberg et al., 2004). Nonetheless, some studies have shown that expressing religious beliefs at the workplace can be destructive because it leads employees to divisiveness and accusations of discrimination (Cavanagh \& Bandsuch, 2002).

Successfully managing diversity appears to be complicated and troublesome when some employees discriminate against each other or when some organizations do not share or embrace their co-workers' beliefs and perceptions. This might affect the employer's unfavorable team outcomes (Van Knippenberg \& Schippers, 2007). It also creates resistance to diversity versus minority among employees (Hostager \& De Meuse, 2008). The vast majority of these studies appear focused on private organizations. They neglect the publicsector organizations, which, similarly, take an essential role in the economy. Hence, studies investigating the relationship between confessional diversity and career satisfaction in public organizations are nonexistent. In this regard, it becomes essential to examine confessional diversity in diverse workforces in the Lebanese Ministry of Finance.

Consequently, the purpose of this study is to establish a correlation between confessional diversity on recruitment and selection, workplace commitment, and career satisfaction at the Lebanese Ministry of Finance.

The COVID-19 pandemic has obstructed the economy globally and affected worker health and mobility. Authorities impose lockdown rules, curfew, and social distancing guidelines to restrain the disease's extent; multiple sectors and business activities have suffered. Accordingly, examining the prevalence of diversity perceptions in the workplace is an important topic to investigate, mainly it influences employees' commitment to remain in their host organization under a pandemic. According to Khalafallah et al. (2020), the rate of career satisfaction was increased compared to rates stated in the pre-COVID era. Therefore, recruitment and affective commitment are likely to become more problematic in a post-pandemic (Filimonau et al., 2020).

This study's significance lies in its attempt to fill the management literature gap, which remains very underdeveloped on confessional diversity matters. The literature also struggles to enhance organizational attentiveness, which can be explained by employees' experiences of career difficulties linked to religious discrimination. Second, it observes the perceptual effects of confessional diversity on recruitment and selection, workplace commitment, and career satisfaction by ignoring merit-based and moral matters that may hinder individuals' career options and opportunities.
The proposed study begins with a literature review on confessional diversity pursued by an overview of the Lebanese community, where the study took place, and a summary of the theoretical background. Next, it includes a review of recruitment and selection procedures in the Lebanese public sector, workplace commitment, career satisfaction, and engagement and draws hypotheses. The methodology is presented, followed by a results discussion, a conclusion, and a section on limitations, implications, and recommendations.

\section{Literature Review and Hypothesis}

This study's conceptual framework examines the impact of confessional diversity on recruitment and selection, workplace commitment, and career satisfaction at the Lebanese Ministry of Finance.

\section{Recruitment and Selection}

Employers look for the most suitable people for particular jobs and positions. Job applicants intend to employ their skills, knowledge, qualifications, and experiences when recruited and selected. The reason they do so is to ensure employment and income. Therefore, practical organization commitment must start with proper recruitment and selection processes followed by employment and evaluations.

The recruitment process provides the job applicant with prospects about what the job requires and what the organization proposes. Organizations aspire to attract and stimulate prospective employees to apply for a job in an organization and satisfy the need for human resources (Fong et al., 2011; Tienari et al., 2002). Therefore, there are various methods of recruitment to fulfill this purpose. Recruitment methods can be either internal or external (Marsden, 1994). Moreover, requirements differ in different work organizations and across different societal environments. Selection involves a set of activities that candidates are screened. Those activities aim at choosing the suitable applicant for the said vacant post (Byars \& Rue, 1997). It is challenging to strike the equilibrium between what the candidate can and wants to do and what the organization requires.

In the public sector, employment was based on the concept of a "career service" of security and permanent employment and was enclosed throughout an internal labor market (Colley, 2001). Therefore, recruitment and selection in the public sector's traditional model is centralized and run by a central public agency (Brown, 2004). Since the public sector is likely to be induced by variables other than profit maximization, government compensation eventually depends on public sector 'workers' capacity to compete over the implementation of human resource management policies that retain, attract, and develop the best talent. 
In Lebanon, the public sector is the main component of the current government and is subjected to religious-political patronage. Such patronage permits politicians to use these offices to return the favor and to reap votes, which carries out conscious and unconscious and official and unofficial activities that affect many aspects of citizens' lives. Applicants in Lebanon are appealed to join the civil service posts because of the wages, which on average are equal to privatesector wages, and because of prestige and security of tenure, civil services jobs guarantee, such as shorter working hours, social and health insurance, and retirement guarantees. To protect the civil service from religious intervention and political pressures, the Lebanese Civil Service Council has set off myriad improvements in its public personnel recruitment practices to attract qualified people from the labor force and assure the merit system.

Hence, equality policies and legislations are unable to tackle certain inequality practices. Various studies on discrimination in recruitment and selection (such as Rooth, 2010; Beattie \& Johnson, 2012) have exposed subliminal and unconscious stereotypes that recruiters employ. Following a set of criteria, inequality and discrimination in recruitment and selection are still evident (Shen et al., 2009). Therefore, discrimination may take various forms. Formal discrimination can affect access to the vital job, compensation, advancement opportunities, and evaluating their performance. Informal discrimination may confront employees once they are employed.

\section{Affective Commitment}

Organizational commitment or employee loyalty is conceptualized as an essential factor influencing organizational effectiveness and employees' well-being. (Meyer \& Herscovitch, 2001) defined commitment as "a force that binds an individual to a course of action of relevance to one or more targets." According to Sheldon's definition, commitment is the identity's connection to the employee with a particular organization (Sheldon, 1971). In particular, organizational commitment commonly refers to an employee's acceptance of and commitment to the organization and the tendency to continually bond oneself with the organization's policies and activities (Kaya \& Ceylan, 2014).

Scholars have made abundant attempts to define the potent relationship between personal factors and organizational commitment. Some researchers contend that people like to belong to groups rather than not belonging (Brewer, 1979). Some indicate that working within a homogenous group, where fellows are similar to the self, is affirmative and helpful for the organization; it also promotes commitment to the workplace (Buckley et al., 2007; Chatman et al., 1998; Godthelp \& Glunk, 2003; Riordan \& Shore, 1997; Tsui et al., 1992). As a result, the more homogeneous the workgroup is, the higher the loyalty (Riordan \& Shore, 1997), group integration between members (O'Reilly et al., 1989), and contribution to the performance will be (Chen et al., 2006). Meyer and Allen (1997) asserted that employees, who were strongly committed to their organizations, get involved in and feel devoted to their organizations. In another study, Ketchand and Strawser (2001) argued that it is critical to have employees committed to their employing organization in order for these organizations to be successful in today's competitive environment.

From the wide variety of definitions found in the literature, organizational commitment represents an individual's psychological link to the entire organization (Baek-Kyoo \& Taejo, 2009) with a strong belief and acknowledgment of its purposes and values in order to attain its goals and to preserve participation (Yousef, 2000).

Meyer and Allen's (1997) framework on organizational commitment proposes three different types of commitment, which encompass the following:

1. Attitudinal or affective commitment is defined as the positive emotional ties to loyalty, identification with, and workplace involvement via positive work experiences.

2. Continuance commitment or turnover attention reflects the perceived economic and social gains versus the possible cost losses of leaving the work.

3. Normative commitment expresses the feeling of obligation and sentiment of pressure to maintain employment.

Affective commitment is considered the most constant and most robust predictor of positive organizational outcomes (Yu, 2005). Therefore, the research paper will discuss affective commitment following the findings of Meyer and Allen (1997). Affective commitment at the workplace is defined as a cheerful devotion among the employee and his organization (Meyer et al., 2006). It possibly affects his/her work contribution and behavioral outcome, which definitely might influence performance and turnover (Avey et al., 2008; Ensher et al., 2001). Affective commitment can be formed through comprehensive communication inside the organization, participating employees in decisionmaking, particularly on their expertise or welfare subjects, and allowing employees to acquire information (Dirani \& Kuchinke, 2011). The feeling of comfort and competence among employees contributes to enhancing affective commitment through human resource management practices and gives their organizations vital competitive advantages (Avey et al., 2008).

However, individuals are discriminated against when they feel denied privileges or rights (Fox et al., 2015), when they are held back by bias (Fuchs et al., 2018), or when they suffer from injustice and insufficient organizational commitment on the part of the victim (Messarra, 2014). The 
feelings of hopelessness, mistrust, despair, alienation, stress, and depression, among others, are common among people who are victims of bias. The negative perceptions are not limited to the working environment, as employees tend to drag those feelings home to their families, friends, and loved ones.

Recruitment and selection could affect employees' affective commitment to remain in the organization (Ashikali \& Groeneveld, 2015). Developing and managing affective commitment starts at recruiting and first entry practices in an institution (Mercurio, 2015). Affective commitment is positively affected when organizations use careful recruitment and selection techniques and create fundamental practices that help new members learn and acquire new organizations' values (Caldwell et al., 1990). Organizations with a high level of affective commitment are organizations that implement socialization experiences for newcomers by defining their role in the organization and familiarizing them with its norms. Relieving anxiety is positively correlated with a commitment to the organization (Meyer et al., 2006).

\section{Career Satisfaction}

A career is a central pillar in every person's path. A career is related to professional activities rather than to extracurricular interests or hobbies. A career does not necessarily have to produce income (Azevedo, 2014). Alboher (2007) examined one person's concept with multiple careers, which is a new model for work and/or life success. In equivalence, one could balance multiple vocations and spread commitment among them rather than primary and secondary engagement (Kirton, 2006). The time and energy that employees devote to their careers depend on the success that they have achieved and the life stage they are in (Alboher, 2007). According to Layder (1993), individuals can hold parallel careers and commit to each of them in equal proportions.

Career satisfaction may be defined as the intensity of happiness a person experiences through his overall occupation choice (Lounsbury et al., 2007). A person might be unsatisfied with his current job experience even though he is confident of making the right career choice (Zingeser, 2004). Maslow's theory (1943) suggested a whole repertoire of needs through which employees could be motivated at all levels of the need hierarchy without paying them more money. Another theory by Locke (1976) highlights the discrepancies between what one wants in a job and what one obtains.

Researchers found that making the wrong career decisions drive people to dissatisfaction with their jobs (Rangel et al., 2018; Wang et al., 2020). Career dissatisfaction is the consequence of making a career decision based only on external factors. (Imel, 2002) strongly argued that some people base their career choices on their aptitudes and circumstances alone and ignore their deep interests, values, and other internal factors. This results in experiencing dissatisfaction with their job. Porter and Steers (1973) reported that dissatisfied employees are less productive and might have a high absence rate while satisfied employees are more innovative, productive, and loyal.

In Lebanon, teaching is the only parallel career a civil servant can practice. Gomez-Mejia et al. (2007) observed a recent change in career development because career paths and opportunities are less conventional and structured than three decades ago. Currently, frequent technological change and downsizing strategies characterize the business world instead of employment security.

Conversely, and as aforementioned, the Lebanese public sector civil servant benefits from career-long tenure, employment security, social and health insurance, and retirement guarantee (Robalino \& Sayyed, 2012). A career focuses on objective and subjective aspects, which were usually restricted to proceeding in organizational hierarchies. Furthermore, fewer career persons struggle to climb up the hierarchical ladder within the boundary and for a life career satisfaction within their professional and private fields.

\section{Confessional Diversity}

Diversity in cultural identities, economic programs, religious beliefs, political systems, and other ethnic groupings is positively correlated with human society and is one of the constants of contemporary life mechanisms. Workforce diversity refers to the coexistence of employees from various perspectives and approaches at a workplace (Ely \& Thomas, 2001) and with different attributes, such as race, gender, ethnicity, language, color, religion, and health status (Kossek et al., 2006; Kreitz, 2008). For a long time, the workplace has been considered a neutral sphere. The relationship between confessional diversity and the workplace was inexistent. However, this relationship has radically changed with globalization, increased immigration, and the importance of science and technology. Nowadays, the workplace is more diversified. Employees come from distinct cultures and ethnic and religious backgrounds. Consequently, they feel more at ease discussing their faith and values at the workplace (Barro \& McCleary, 2003; Cantone \& Wiener, 2017; Dean et al., 2014), and they are no longer satisfied with keeping their religious beliefs outside their working environment. This could be valid for the Lebanese republic with its unique cultural values, combined with a conflicting organizational environment that might ruin outcomes.

Religion has been known as one of the significant elements that influence an individual's value system and, consequently, shapes an organization's cultural environment (Kutcher et al., 2010). After September 11, 2001, the incidents of religious discrimination for the minorities in 
western democracies, especially against Muslims, flourished (Akbaba, 2009; Ali et al., 2015; Oskooii, 2016). Subsequently, most western researchers and practitioners have perceived this rise of confessional working diversity as a new managerial challenge, which needs to be attended to.

\section{Confessional Diversity in Lebanon}

Understanding the history of Lebanon permits a deeper understanding of why confessional diversity still exists. Lebanon, a small country located on the eastern shore of the Mediterranean Sea, is incredibly diverse culturally, religiously, and politically. The Lebanese regime is based on two primary documents, written and unwritten, and some customary rules. The Constitution, established in 1926, developed throughout the French mandate, was amended several times. Later, it was represented in the Charter of 1943, after the Lebanese independence. New amendments have been made after that, which were concerned with particular constitutional rules (Salem, 1997). The political power and governmental positions in the country were shared informally on a confessional basis. Such that the President of the Republic, the Commander-in-Chief of the army, and the Central Bank are always Maronite Christians, the Prime Minister is Muslim Sunni, the Speaker of the Parliament Muslim Shi'ite, and all the other governmental and military offices and posts are proportionally shared by the various communities (Bali \& Lerner, 2016). It is evident from the preceding that the National Charter was a clear expression of the state of division in Lebanese society. It was an expression of the confessional diversity and its impact on the Lebanese political system. According to the old Constitution, seats in the parliament and other public administration positions were distributed through the demographic situation in 1932 according to a ratio of 6 Christians to 5 Muslims (Knio, 2005).

After that, the National Charter was the subject of another amendment through an agreement known as "The Taif Accord." The Accord was held under the auspices of Saudi Arabia in 1989. It officially ended the civil war and reasserted the confessional formula. The Taif Accord expressly granted a 50/50 ratio of representation between Muslims and Christians. The power remained between the "triumvirates," the President as a Maronite Christian, the Prime Minister Head of Government as a Muslim Sunni, and the Parliament's Speaker as a Muslim Shi' ite. However, the 126 seats in the parliament and all other ministries, posts, offices, diplomatic corps, and government positions were allocated proportionally according to sectarian affiliation among Christians and Muslims, as indicated by their demographic proportion in the country (Badaan et al., 2020).

Consequently, the Lebanese government now formally acknowledges and respects each confessional community's right by securing an assumed fair sharing of institutional, political, economic, and social power. Currently, recruitment and selection in the Lebanese public sector are based on mandatory confessional diversity to ensure fair representation of all religious groups (Hudson, 1999).

Societies with little or no control of confessional diversity may yield inequality, imbalance, or participation deficiency. A study done on the workforce shows that minorities are more likely to change jobs when they perceive discrimination. This results in work with less affective commitment (Shoobridge, 2006). Moreover, the danger arises when individuals sense mistreatment or discrimination due to their religious affiliation. Individuals would, thus, develop poor work-related behaviors, such as selfdoubt, low confidence, and detaching oneself from the job.

Hence, we hypothesized that:

H1: Recruitment and selection have a positive and significant influence on affective commitment.

$\mathrm{H} 2$ : Affective commitment has a positive and significant influence on career satisfaction.

H3: Confessional diversity has a positive and significant influence on recruitment and selection (staffing).

$\mathrm{H} 4$ : Confessional diversity has a positive and significant influence on affective commitment.

H5: Confessional diversity has a positive and significant influence on career satisfaction.

\section{Method}

\section{Procedures}

The sampling method employed is purposive sampling. Participants needed to hold specific attributes to qualify for the study. Principally, the participants are of Lebanese nationality and work within the Ministry of Finance in Lebanon. Having satisfied those two criteria, participants were able to partake. The proposed study respects the necessary ethical considerations. A letter was sent to the Ministry of Finance's higher management. The letter sought the management's consent about distributing the proposed rating scale within the Ministry's entourage. The rating scales were circulated and completed to succeed the consent. Participants were informed that their information would be kept confidential to guarantee anonymity. Names and/or details revealing personal information were not required. Moreover, participation was entirely voluntary, and participants were allowed to withdraw at any point should the need arise. 


\section{Sample}

Participants within the Lebanese Ministry of Finance were randomly selected and invited to participate. Questionnaires were distributed and collected in person during January 2021. A total of 195 surveys were distributed to employees from different categories working in the Ministry. Out of those, 179 were returned, out of which 20 surveys were incomplete and were not included in the research. As a result of the outlier check, 159 surveys retained, indicating a 79.5\% response rate. This study's sample profile, regarding gender, age, marital status, religion, educational level, job category, and tenure, is presented in Table 1 below.

The sample included 159 participants which revealed that $54.7 \%$ were male. $68 \%$ of the participants are married. The mean age was 39 years (standard deviation $=0.672$ ). Participants' religion was $57.9 \%$ Christian, and $42.1 \%$ were Muslims. The majority holds a university degree, and they were in the fourth category with $66.1 \%$. Lastly, $44 \%$ of employees have 12 to 19 years of experience.

\section{Measurement}

The researcher assembled the set into one document for convenience purposes. Nonetheless, the assembled document incorporates demographic details and 32 questions that express four sections. Each section deals with a different concept within the study. The relevant surveys were translated from the source language into the target language using the back translation process (Brislin, 1970). Back translation was used in this study to create an Arabic version and then return it to the English version to check equivalence. A pilot sample was developed and distributed to 5 employees at the Lebanese Ministry of Finance to ensure the understandability of questionnaire items.

Measures were adopted in the present study from the relevant literature (see Appendix 1). Participants are first asked to respond to a range of demographic questions, including gender, age, marital status, religious sect, educational level, position, and tenure. Demographic characteristics of participants are supposed to have explanatory value in the research (Tsui, 1990). Respondents are also asked to rate the items according to the five-point Likert scales ranging from "strongly agree" to "strongly disagree." For each item within the rating scale, participants were asked to choose one impression only.

\section{Recruitment and Selection}

An adapted and shortened form of the Edgar and Geare HRM practice questionnaire (Edgar \& Geare, 2005) was used. The scale has four items that precisely captures the core measures necessary to assessed the strength of recruitment and selection process in the Lebanese Public Sector (the recruitment and selection process in this organization are impartial; all appointments in this organization are based on merit; this organization does not need to pay more attention to the way it recruits people; favoritism is not evident in any of the recruitment decisions made here).

\section{Affective Commitment}

Meyer et al.'s (2006) integrative process model that consists of six items was used to measure affective commitment.

\section{Career Satisfaction}

The employee's career satisfaction was operationalized using six items based on the study of Greenhaus et al. (1990).

\section{Confessional Diversity}

Confessional diversity was assessed through 16 items derived from Messarra and El Kassar's (2010) study on religious diversity.

\section{Data Analysis}

Once data was collected, the documents' ratings were admitted using the partial least squares structural equation modeling (PLS-SEM) by using version 3.0 of the SmartPLS as a statistical analysis platform (Ringle \& Sarstedt, 2016) and

Table 1 Sample profile

\begin{tabular}{|c|c|c|c|c|}
\hline Total respondents & 159 & & & \\
\hline Gender & Male (54.7\%) & & & Female (42.3\%) \\
\hline Age & $18-25(4.5 \%)$ & $26-35(30.3 \%)$ & $36-50(55.4 \%)$ & $51-64(8.8 \%)$ \\
\hline Marital status & Single $(30.8 \%)$ & Married (68\%) & & Divorced (1.2\%) \\
\hline \multirow[t]{2}{*}{ Religion } & Maronite (29\%) & Catholic (19.5\%) & & Orthodox (9.4\%) \\
\hline & Druze $(8.2 \%)$ & Shia (22\%) & & Sunni (12.6\%) \\
\hline Educational level & Technical (10\%) & & & University $(90 \%)$ \\
\hline Grade & Two $(3.7 \%)$ & Three $(28.3 \%)$ & Four (66.1\%) & Five $(1.9 \%)$ \\
\hline Tenure & $0-5(15 \%)$ & $6-11(25.5 \%)$ & $12-19(44 \%)$ & More than $20(15.5 \%)$ \\
\hline
\end{tabular}


following the 2 step method (Hair et al., 2011). The first step involves assessing the psychometric properties of the measurement model, and the second step, the analysis of the hypothesis of our structural model.

Connections and correlations were then concluded to reject or accept each of the mentioned hypotheses. Those are included in the discussion section. The main reason the use PLS-SEM platform was employed is to ensure the accuracy of attained results. PLS-SEM is recommended for the following conditions; accurate results are derived, no need for large sample sizes, evades limitations or incidences linked to model identification, model complexity, measurement levels, and factor indeterminacy (Hair et al., 2017).

\section{Reliability and Validity}

Specific factors to the instrument employed to warrant the study's reliability and validity. Consistency in the instrument's findings renders reliable (Gomes et al., 2015), and the effectiveness in measuring what is chosen for the instrument to measure deems the study a valid one. The factor loadings score for all constructs was above 0.5 suggested by (Hulland, 1999; Truong \& McColl, 2011), except for nine items score Q24, Q27, Q29, Q31, Q32, Q33, Q34, Q35, and Q39. Cronbach's alpha and Composite Reliability (CR) are used to measure consistent reliability. Convergent validity was measured using the AVE that tests the correlation between the items for the same construct (Hair Jr et al., 2016). The minimum acceptable AVE is 0.50 or higher. Values are presented in Table 2.

Next, we determine the discriminant validity, which is the extent to which a construct is empirically distinct from other structural models' constructs. According to Fornell and Larcker (1981), we compared the AVE of each construct with the squared inter-construct correlation of that same construct and with all other reflectively measured constructs in the structural model. As shown in Table 3 below, AVE's square root for all constructs needed to be higher than the inter-construct correlation for each construct in our measurement model. Therefore, using Fornell and Larcker's (1981) criterion, we confirm all constructs' discriminant validity in our model.

Finally, we measured the collinearity and multicollinearity between and among the predictor variables by examining the variance inflation factor (VIF) values as shown in the table below. The results show that all of the VIF values fell
Table 2 Descriptive Statistics and Reliability/Validity Indicators

\begin{tabular}{|c|c|c|c|c|c|c|}
\hline Variables Name & Item & $\begin{array}{l}\text { Loadings } \\
\lambda\end{array}$ & Mean & S.D & Kurtosis & Skewness \\
\hline \multirow[t]{4}{*}{ Recruitment and Selection } & 8 & 0.678 & 2.885 & 1.098 & -1.247 & 0.087 \\
\hline & 9 & 0.763 & 2.354 & 1.080 & -0.840 & 0.561 \\
\hline & 10 & 0.651 & 2.385 & 0.993 & -0.295 & 0.518 \\
\hline & 11 & 0.775 & 2.323 & 1.094 & -0.443 & 0.633 \\
\hline \multirow[t]{6}{*}{ Affective Commitment } & 12 & 0.756 & 3.615 & 0.961 & 0.400 & -0.940 \\
\hline & 13 & 0.786 & 3.344 & 0.977 & -0.524 & -0.470 \\
\hline & 14 & 0.720 & 2.552 & 1.079 & -0.627 & 0.622 \\
\hline & 15 & 0.797 & 2.521 & 1.090 & -0.600 & 0.609 \\
\hline & 16 & 0.816 & 3.458 & 1.060 & -0.112 & -0.849 \\
\hline & 17 & 0.715 & 2.427 & 1.048 & -0.330 & 0.775 \\
\hline \multirow[t]{6}{*}{ Career Satisfaction } & 18 & 0.725 & 3.354 & 1.099 & -0.695 & -0.697 \\
\hline & 19 & 0.842 & 3.115 & 1.114 & -1.237 & -0.271 \\
\hline & 20 & 0.612 & 2.885 & 1.189 & -1.440 & -0.228 \\
\hline & 21 & 0.739 & 2.500 & 1.099 & -1.322 & 0.287 \\
\hline & 22 & 0.709 & 2.865 & 1.124 & -1.394 & -0.086 \\
\hline & 23 & 0.767 & 3.094 & 1.100 & -1.091 & -0.523 \\
\hline \multirow[t]{7}{*}{ Confessional Diversity } & 25 & 0.603 & 2.438 & 1.078 & -0.549 & 0.620 \\
\hline & 26 & 0.565 & 2.146 & 0.989 & 0.450 & 0.946 \\
\hline & 28 & 0.761 & 2.438 & 1.069 & -0.479 & 0.712 \\
\hline & 30 & 0.622 & 2.146 & 1.190 & -0.013 & 0.918 \\
\hline & 36 & 0.614 & 1.677 & 0.714 & 2.458 & 1.268 \\
\hline & 37 & 0.771 & 2.323 & 1.085 & -0.598 & 0.616 \\
\hline & 38 & 0.600 & 2.562 & 1.171 & -1.031 & 0.401 \\
\hline
\end{tabular}

*** $=p<0.001$. Items excluded as a result of low loadings: Q24, Q27, Q29, Q31, Q32, Q33, Q34, Q35 and Q39 
Table 3 Discriminant ValidityFornell and Larcker's criterion

\begin{tabular}{lllllllll}
\hline Constructs & CA & rho & CR & AVE & AC & CS & CD & R\&S \\
\hline AC & -0.547 & 0.874 & 0.003 & 0.595 & ${ }^{\mathrm{a}} 0.772$ & 0.618 & 0.477 & 0.316 \\
CS & 0.830 & 0.849 & 0.875 & 0.541 & 0.556 & 0.736 & 0.449 & 0.489 \\
CD & 0.785 & 0.811 & 0.837 & 0.426 & -0.411 & -0.376 & 0.653 & 0.518 \\
R\&S & 0.696 & 0.710 & 0.810 & 0.517 & 0.255 & 0.394 & -0.291 & 0.719 \\
\hline
\end{tabular}

$\boldsymbol{C A}$ Cronbach's alpha, $\boldsymbol{C R}$ Composite reliability, rho rho_A reliability indices, $\boldsymbol{A V E}$ Average variance extracted $^{\mathbf{a}}=$ Diagonal values in bold are the square root of AVE, ${ }^{\mathbf{b}}=$ Italicized values above the square root of AVE are Heterotrait-Monotrait (HTMT) ratios
Table 4 Structural model multicollinearity (VIF values)

\begin{tabular}{llll}
\hline Constructs & AC & CS & R\&S \\
\hline $\mathrm{CD}$ & 1.160 & 1.313 & 1 \\
\hline
\end{tabular}

under 3, reflecting the absence of collinearity or multicollinearity issues between and among the independent variables in our hypothesized model (Mason \& Perreault Jr, 1991; Becker et al., 2015) (Table 4).

\section{Evaluating the Structural Model}

After checking the validity and reliability of the measurement model in the previous stage of the analysis, we proceed in the second stage to test whether the structural model's formulated hypotheses are statistically significant or otherwise. The evaluation was done under the guidance of Hair et al. (2019) through the examination of path coefficients $\beta$, the $R 2$ values, the $\mathrm{t}$-values, predictive relevance $(Q 2)$, and effect sizes $(f 2)$ which is ensured in Table 5 given below.

We find that recruitment and selection have no positive and significant effect on affective commitment $(\beta=0.107$, $\mathrm{p}>0.05)$. In contrast, we find that affective commitment positively and significantly affects career satisfaction $(\beta=0.442, p<0.05)$. We also find Confessional diversity also had a positive and significant effect on recruitment and selection $(\beta=0.353, p<0.05)$, on affective commitment $(\beta=0.403, p<0.05)$. Confessional diversity was found to positively affect career satisfaction $(\beta=0.249$, $p<0.05)$. However, according to the recommendations of Hair et al. (2019), we observed the beta coefficients $(\beta)$, statistical significance ( $P$-value), and $(R 2)$ value. Also, we interpret the substantive significance $(f 2)$ reflected as the effect sizes, values higher than $0.02,0.15$, and 0.35 , depict small, medium, and significant effects size, respectively (Sullivan \& Feinn, 2012).

Finally, we used the PLS predict functionality in SmartPLS to observe the outcome variable's predictive validity in our study model (Shmueli et al., 2016). The PLS predict analysis yielded $Q 2$ values for each of the constructs as follows affective commitment $(0.115)$, career satisfaction (0.108), and recruitment and selection (0.047). Since they are all greater than zero, it signals the model's sufficient predictive relevance and predictive validity. However, while the obtained error summary statistics, including the root mean squared error (RMSE), and the mean absolute error (MAE) values, were compared to the linear regression model (LM) that mean that the model has high predictive power, as shown in Table 6 below (Shmueli et al., 2019).

Table 5 Results of the path analysis

\begin{tabular}{lllllll}
\hline \multirow{2}{*}{ Hypothesis } & \multicolumn{4}{l}{ Model Fit Indices: SRMR $=0.102 ;$ NFI=0.514 } \\
\cline { 2 - 7 } & $\begin{array}{l}\beta \\
\text { values }\end{array}$ & $\begin{array}{l}t \\
\text { statistics }\end{array}$ & $\begin{array}{l}p \\
\text { values }\end{array}$ & $f^{2}$ & $R^{2}$ & Results \\
\hline H1: Recruitment \& selection - > affective commitment. & 0.107 & 0.987 & 0.162 & 0.013 & 0.398 & Not Supported \\
H2: Affective commitment - > career satisfaction. & 0.442 & 2.142 & 0.020 & 0.244 & 0.600 & Supported \\
H3: Confessional diversity - > recruitment and selection & 0.353 & 2.126 & 0.017 & 0.143 & 0.338 & Supported \\
H4: Confessional diversity - > affective commitment. & 0.403 & 1.724 & 0.042 & 0.179 & 0.398 & Supported \\
H5:Confessional diversity- > career satisfaction. & 0.249 & 1.808 & 0.035 & 0.077 & 0.600 & Supported \\
\hline
\end{tabular}

$p<0.05$, one tailed 
Table 6 PLS Predict Analysis

\begin{tabular}{llll}
\hline Latent Construct Prediction Summary & RMSE & MAE & $\mathrm{Q}^{2}$ \\
\hline Affective Commitment & 0.963 & 0.733 & 0.115 \\
Career Satisfaction & 0.966 & 0.802 & 0.108 \\
Recruitment and Selection & 0.999 & 0.785 & 0.047 \\
\hline
\end{tabular}

Theoretical Framework Model (Fig. 1)

\section{Discussion}

Our research's crucial purpose was to suggest a research model concerning the effect of confessional diversity on recruitment and selection, affective commitment, and career satisfaction. The employment system in the Lebanese public sector is centralized through central organizations that were responsible for settling recruiting process, hiring decisions, and formulating rules for employment, training, and career development. Data acquired from employees in the Lebanese Ministry of Finance were selected to measure the hypothesized relationships. First, the results verified negative support between the recruitment and selection and the affective commitment, which explains how employees in the public sector in Lebanon experience difficulties related to the affective commitment. Simultaneously, recruitment and selection in the public sector focus on attracting qualified people and ensuring the merit system. Hence, these policies and legislations are not capable of practice to tackle certain inequality practices. Therefore, the individuals' qualifications like the level of education or the years of professional experience are ignored during the recruitment and selection process, which may confront employees' affective commitment once they are employed. Second, affective commitment represents the love of belonging to an organization, and this feeling could not be expressed from the recruitment process, but it develops through time. This positive feeling towards the organization is related to the correct way in which the employees are treated. Accordingly, this means that the recruitment and selection process in the Lebanese public sector was very weak to influence affective commitment which is interpreted as the employee's emotional attachment, identification, and involvement within the organization. Concerning the relation between affective commitment and career satisfaction, this study shows a positive relationship between them (which is consistent with the proposed hypothesis). As affective commitment refers to emotional attachment to the workplace, employees with a high level of affective commitment do not

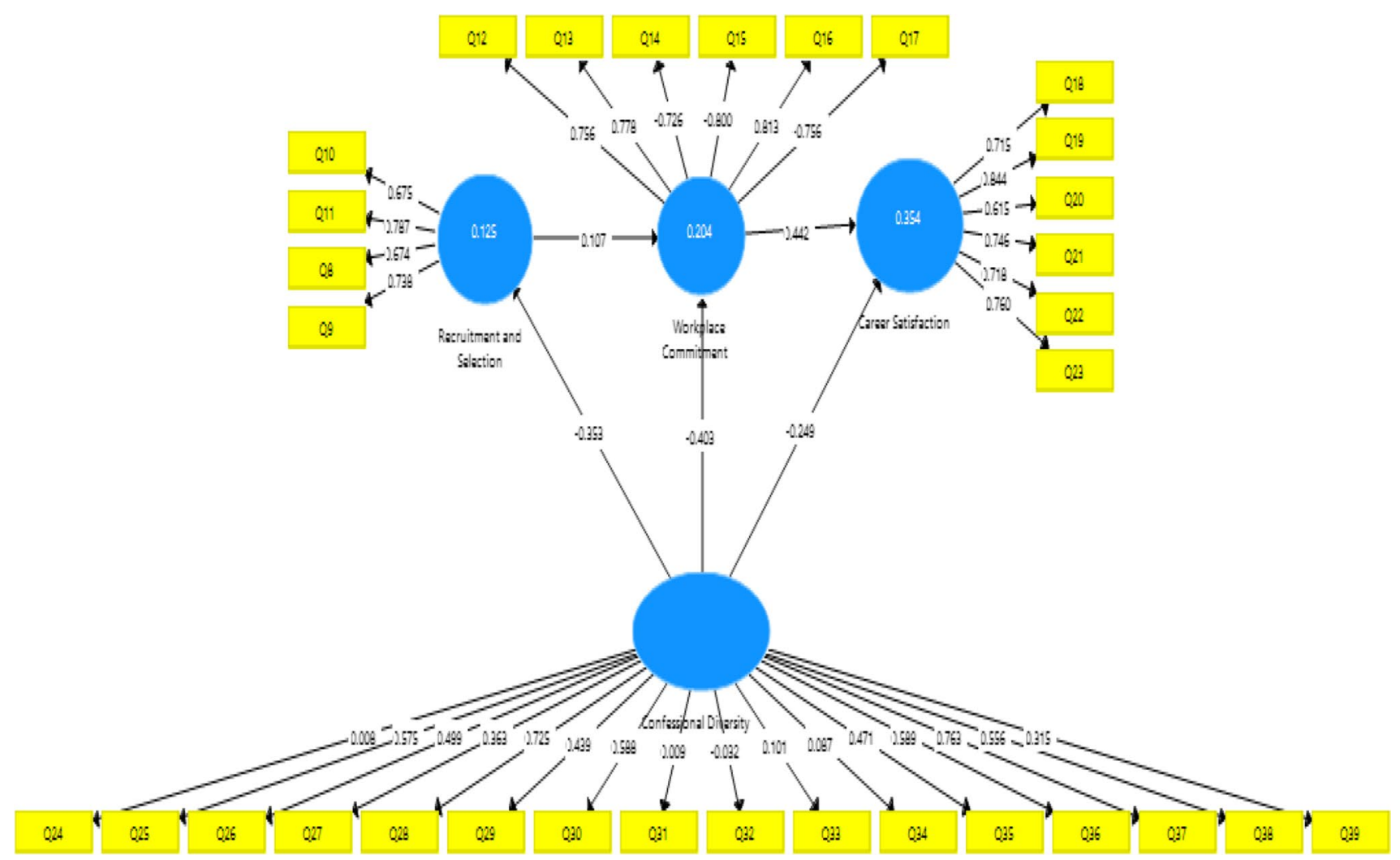

Fig. 1 Smart PLS Model image 
plan to change their career, and they perceive that changing a career will be costly to them. Furthermore, the current study added to the literature and got similar results; that affective commitment positively impacts career satisfaction (Makhathini \& Van Dyk, 2018). In this setting, employment in the Lebanese public sector is characterized by the traditional notions of career service, stability, and lifetime employment. This study investigates the impact of confessional diversity on recruitment and selection, affective commitment, and career satisfaction. The result indicates a positive and significant impact of confessional diversity on all these variables. The applicant's sect and bias often influence the recruitment and selection process in the Lebanese public sector, which means that confessional differences between applicant groups are amplified. The result is that applicants' selection is often assessed based on their confessions to which they belong, especially for high category jobs. This study also suggested that when employees are selected according to recruitment and selection process that promote confessional diversity and support the idea that diversity is an opportunity and not a problem (Cox, 1994), can mitigate the potential problems on affective commitment and career satisfaction are influenced positively by the confessional diversity.

The problems besetting the public sector required a different model for operating this sector. Our results have important implications for the Lebanese public sector. The promotion of confessional diversity among employees in the Lebanese public sector should be further connected with merit-based treatment rather than to the sects to which they belong. Concurrently, it is clear from this study that policies and legislations should implement effective HRM practices that take into consideration the level of education or the years of professional experience during the recruitment and selection process, particularly for high category jobs. The evidence shows that securing equal and equitable opportunities is a necessity for the Lebanese public administrative reforms, while neglecting equality may waste talented employees by mitigating emotional attachment and career satisfaction.

\section{Limitations}

This current study has several limitations. First, this data was collected from a small sample size from the public sector in Lebanon. Therefore, the results cannot be generalized on a larger scale. Further research is needed to extend this study to other cultures and identify differences between the private and public sectors. Second, further studies could assess the effect of confessional diversity on other behavioral outcomes, such as turnover, coping with change, and job satisfaction. Finally, continuance and normative commitments were not included in this research. However, future research should consider the continuance and normative commitment and their interactions with the other study variables.

\section{Conclusions}

Drawing from the above discussion, it can be concluded that studying the impact of confessional diversity in the Lebanese public sector was a challenge. However, the attachment of Lebanese people to religious identity and confession is more rooted at the expense of national commitment. Confessional diversity leads to inequalities. Accordingly, solutions or recommendations for confessional diversity issues in the Lebanese public sector are related to the national, educational, and social levels. Recruitment and selection in a sectarian environment affect the quality of personnel recruited into the public sector. Therefore, it is recommended to implement effective recruitment and selection practices based on evaluating candidates' skills and carrying out background checks rather than on the sects to which they belong. These effective recruitment and selection practices can provide some equal employment opportunities.

Supplementary Information The online version contains supplementary material available at https://doi.org/10.1007/s12144-022-02823-7.

Data Availability The data that support the findings of this study are available from the corresponding author upon reasonable request.

\section{Declarations}

Ethics Approval All procedures performed in this study involving human participants were under the institutional and/or national research committee's ethical standards and the 1964 Helsinki declaration and its later amendments or comparable ethical standards.

Consent to Participate All study participants consented to participate in the study.

Consent for Publication Author consented to the publication of this article.

Conflict of Interest Author declares that he has no conflicts of interested.

\section{References}

Akbaba, Y. (2009). Who Discriminates More? Comparing Religious Discrimination in Western Democracies, Asia and the Middle East. Civil Wars, 11(3), 321-358. https://doi.org/10.1080/13698 240903157578

Alboher, M. (2007). One person multiple careers. PT Mizan Publika. Ali, S. R., Yamada, T., \& Mahmood, A. (2015). Relationships of the practice of hijab, workplace discrimination, social class, job stress, and job satisfaction among Muslim American women. Journal of Employment Counseling, 52(4), 146-157. 
Ashikali, T., \& Groeneveld, S. (2015). Diversity management in public organizations and its effect on employees' affective commitment: The role of transformational leadership and the inclusiveness of the organizational culture. Review of Public Personnel Administration, 35(2), 146-168.

Avey, J. B., Wernsing, T. S., \& Luthans, F. (2008). Can positive employees help positive organizational change? Impact of psychological capital and emotions on relevant attitudes and behaviors. Journal of Applied Behavioral Science, 44(1), 48-70.

Azevedo, M. C. B. (2014). Parallel careers and their consequences for companies in Brazil. BAR-Brazilian Administration Review, 11(2), 125-144.

Badaan, V., Richa, R., \& Jost, J. T. (2020). Ideological justification of the sectarian political system in Lebanon. Current Opinion in Psychology, 32, 138-145.

Baek-Kyoo, B. J., \& Taejo, L. (2009). The effects of an organizational learning culture, perceived job complexity, and proactive personality on organizational commitment and intrinsic motivation. Journal of Leadership and Organizational Studies, 16(1), 48-60.

Bali, A. U., \& Lerner, H. (2016). Constitutional Design Without Constitutional Moments: Lessons from Religiously Divided Societies. Cornell Int'l LJ, 49, 227.

Barro, R., \& McCleary, R. (2003). Religion and economic growth across countries. American Sociological Review, 68(5), 760-781.

Beattie, G., \& Johnson, P. (2012). Possible unconscious bias in recruitment and promotion and the need to promote equality. Perspectives: Policy and Practice in Higher Education, 16(1), 7-13. https://doi.org/10.1080/13603108.2011.611833

Becker, S., Müller, J., de Heer, G., Braune, S., Fuhrmann, V., \& Kluge, S. (2015). Clinical characteristics and outcome of very elderly patients $\geq 90$ years in intensive care: a retrospective observational study. Annals of Intensive Care, 5(1), 1-8.

Beyer, P., \& Beaman, L. G. (2019). Dimensions of diversity: toward a more complex conceptualization. Religious, 10(10), 559

Brewer, M. B. (1979). In-group bias in the minimal intergroup situation: A cognitive-motivational analysis. Psychological Bulletin, $86,307-324$.

Brislin, R. W. (1970). Back-translation for cross-cultural research. Journal of Cross-Cultural Psychology, 1(3), 185-216.

Brown, K. (2004). Human resource management in the public sector. Public Management Review, 6(3), 303-309.

Buckley, M. R., Jackson, K. A., Bolino, M. C., Veres, J. G., \& Feild, H. S. (2007). The influence of relational demography on panel interview ratings: A field experiment. Journal of Personnel Psychology, 60, 627-646.

Byars, L. L., \& Rue, L. W. (1997). Human Resource Management. irwin.

Caldwell, D. F., Chatman, J. A., \& O'Reilly, C. A. (1990). Building organizational commitment: A multifirm study. Journal of Occupational Psychology, 63(3), 245-261.

Cantone, J. A., \& Wiener, R. L. (2017). Religion at work: Evaluating hostile work environment religious discrimination claims. Psychology, Public Policy, and Law, 23(3), 351.

Cavanagh, G. F., \& Bandsuch, M. R. (2002). Virtue as a benchmark for spirituality in business. Journal of Business Ethics, 38(1), 109-117.

Chatman, J. A., Polzer, J. T., Barsade, S. G., \& Neale, M. A. (1998). Being different yet feeling similar: The influence of demographic composition and organizational culture on work processes and outcomes. Administrative Science Quarterly, 43, 749-780.

Chen, J., Silverthorne, C., \& Hung, J. (2006). Organization communication, job stress, organizational commitment, and job performance of accounting professionals in Taiwan and America. Leadership and Organization Development Journal, 27(4), 242-249.

Colley, L. (2001). The changing face of public sector employment. Australian Journal of Public Administration, 60(1), 9-20.
Cox, T. (1994). Cultural diversity in organizations: Theory, research and practice. Berrett-Koehler Publishers.

Dean, K. L., Safranski, S. R., \& Lee, E. S. (2014). Religious accommodation in the workplace: understanding religious identity threat and workplace behaviors in legal disputes. Employee Responsibilities and Rights Journal, 26(2), 75-94.

Dirani, K. M., \& Kuchinke, K. P. (2011). Job satisfaction and organizational commitment: validating the Arabic satisfaction and commitment questionnaire (ASCQ), testing the correlations, and investigating the effects of demographic variables in the Lebanese banking sector. The International Journal of Human Resource Management, 22(05), 1180-1202.

Edgar, F., \& Geare, A. (2005). HRM practice and employee attitudes: different measures - different results. Personnel Review, 34(5), 534-549.

Ely, R. J., \& Thomas, D. A. (2001). Cultural diversity at work: The effects of diversity perspectives on work group processes and outcomes. Administrative Science Quarterly, 46(2), 229-273.

Ensher, E. A., Grant-Vallone, E. J., \& Donaldson, S. I. (2001). Effects of perceived discrimination on job satisfaction, organizational commitment, organizational citizenship behavior, and grievances. Human Resource Development Quarterly, 12(1), 53-72.

Esty, K., Griffin, R., \& Hirsch, M. S. (1995). A manager's guide to solving problems and turning diversity into a competitive advantage: Workplace diversity. Adams Media.

Filimonau, V., Derqui, B., \& Matute, J. (2020). The COVID-19 pandemic and organisational commitment of senior hotel managers. International Journal of Hospitality Management, 91, 102659.

Fong, C., Ooi, K., Tan, B., Lee, V., \& Chong, A. (2011). HRM practices and knowledge sharing: an empirical study. International Journal of Manpower, 32(5/6), 704-723.

Fornell, C., \& Larcker, D. F. (1981). Structural equation models with unobservable variables and measurement error: Algebra and statistics.

Fox, J. E., Moroşanu, L., \& Szilassy, E. (2015). Denying discrimination: Status, 'race', and the whitening of Britain's new Europeans. Journal of Ethnic and Migration Studies, 41(5), 729-748.

Fuchs, C. S., Doi, T., Jang, R. W., Muro, K., Satoh, T., Machado, M., ... Yoon, H. H. (2018). Safety and efficacy of pembrolizumab monotherapy in patients with previously treated advanced gastric and gastroesophageal junction cancer: phase 2 clinical KEYNOTE-059 trial. JAMA Oncology, 4(5), e180013-e180013.

Godthelp, M., \& Glunk, U. (2003). Turnover at the top: Demographic diversity as a determinant of executive turnover in the Netherlands. European Management Journal, 12, 614-636.

Gomes, J. B., Cordioli, A., Van Noppen, B., Pato, M., Wolitzky-Taylor, K., Gonçalves, F., \& Heldt, E. (2015). Family Accommodation Scale for Obsessive-Compulsive Disorder-Interviewer-Rated (FAS-IR), Brazilian Portuguese version: Internal consistency, reliability, and exploratory factor analysis. Comprehensive Psychiatry, 57, 155-159.

Gomez-Mejia, L. R., Balkin, D. B., Cardy, R. L., \& Carson, K. P. (2007). Managing human resources. Pearson/Prentice Hall.

Greenhaus, J. H., Parasuraman, S., \& Wormley, W. M. (1990). Effects of race on organizational experiences, job performance evaluations, and career outcomes. Academy of Management Journal, 33(1), 64-86. https://doi.org/10.5465/256352

Griffin, K. A., Cunningham, E. L., \& George Mwangi, C. A. (2016) Defining diversity: Ethnic differences in Black students' perceptions of racial climate. Journal of Diversity in Higher Education, 9(1), 34-49.

Hair, J. F., Jr., Sarstedt, M., Matthews, L. M., \& Ringle, C. M. (2016). Identifying and treating unobserved heterogeneity with FIMIXPLS: part I-method. European Business Review, 31(1), 2-24. https://doi.org/10.1108/EBR-11-2018-0203 
Hair, J. F., Ringle, C. M., \& Sarstedt, M. (2011). PLS-SEM: Indeed a silver bullet. Journal of Marketing Theory and Practice, 19(2), 139-152.

Hair, J. F., Hult, G. T. M., Ringle, C. M., Sarstedt, M., \& Thiele, K. O. (2017). Mirror, mirror on the wall: a comparative evaluation of composite-based structural equation modeling methods. Journal of the Academy of Marketing Science, 45(5), 616-632.

Hair, J. F., Risher, J. J., Sarstedt, M., \& Ringle, C. M. (2019). When to use and how to report the results of PLS-SEM. European Business Review.

Hambler, A. (2015). Managing workplace religious expression within the legal constraints. Employee Relations, 38(3), 406-419.

Hanf, T. (2015). Coexistence in wartime Lebanon: decline of a state and rise of a nation. IB Tauris.

Hofstede, G. (2007). Asian management in the 21st century. Asia Pacific Journal of Management, 24(4), 411-420.

Hostager, T. J., \& De Meuse, K. P. (2008). The effects of a diversity learning experience on positive and negative diversity perceptions. Journal of Business and Psychology, 23(3), 127-139.

Hudson, M. C. (1999). Lebanon after Ta'if: another reform opportunity lost? Arab Studies Quarterly, 27-40. https://www.jstor.org/ stable/41858274.

Hulland, J. (1999). Use of partial least squares (PLS) in strategic management research: A review of four recent studies. Strategic Management Journal, 20(2), 195-204.

Ilgen, D. R., Hollenbeck, J. R., Johnson, M., \& Jundt, D. (2005). Teams in organizations: from input-process-output models to IMOI models. Annual Review of Psychology, 56, 517-543.

Imel, S. (2002). Career development for meaningful life work (Vol. 237). ERIC Clearinghouse on Adult, Career, and Vocational Education.

Jurkiewicz, C., \& Giacalone, R. (2004). A Values Framework for Measuring the Impact of Workplace Spirituality on Organizational Performance. Journal of Business Ethics, 49(2), 129-142.

Kaya, C., \& Ceylan, B. (2014). An empirical study on the role of career development programs in organizations and organizational commitment on job satisfaction of employees. American Journal of Business and Management, 3(3), 178-191.

Ketchand, A. A., \& Strawser, J. R. (2001). Multiple dimensions of organizational commitment: implications for future accounting research. Behavioral Research in Accounting, 13, 221-251.

Khalafallah, A. M., Lam, S., Gami, A., Dornbos, D. L., III, Sivakumar, W., Johnson, J. N., \& Mukherjee, D. (2020). Burnout and career satisfaction among attending neurosurgeons during the COVID-19 pandemic. Clinical Neurology and Neurosurgery, $198,106193$.

Kirton, G. (2006). Alternative and parallel career paths for women: the case of trade union participation. Work, Employment and Society, 20(1), 47-65.

Knio, K. (2005). Lebanon: Cedar Revolution or Neo-Sectarian Partition? Mediterranean Politics, 10(2), 225-231.

Koenig, H. G. (1995). Religion as cognitive schema. International Journal for the Psychology of Religion, 5(1), 31-37.

Koopmans, R., \& Schaeffer, M. (2016). Statistical and perceived diversity and their impacts on neighborhood social cohesion in Germany, France and the Netherlands. Social Indicators Research, 125(3), 853-883.

Kossek, E. E., Lobel, S. A., \& Brown, J. (2006). Human resource strategies to manage workforce diversity. Handbook of workplace diversity, 53-74.

Kreitz, P. A. (2008). Best Practices for Managing Organizational Diversity. The Journal of Academic Librarianship, 34(2), 101-120.

Kutcher, E. J., Bragger, J. D., Rodriguez-Srednicki, O., \& Masco, J. L. (2010). The role of religiosity in stress, job attitudes, and organizational citizenship behavior. Journal of Business Ethics, 95(2), 319-337.
Layder, D. (1993). New strategies in social research: An introduction and guide. Polity Press.

Li, Y., \& Heath, A. F. (2016). Class matters: A study of minority and majority social mobility in Britain, 1982-2011. American Journal of Sociology, 122(1), 162-200.

Locke, E. A. (1976). The nature and causes of job satisfaction. Handbook of industrial and organizational psychology.

Lounsbury, J. W., Moffitt, L., Gibson, L. W., Drost, A. W., \& Stevens, M. (2007). An investigation of personality traits in relation to job and career satisfaction of information technology professionals. Journal of Information Technology, 22(2), 174-183.

Makhathini, T. N., \& Van Dyk, G. A. (2018). Organisational climate, job satisfaction, and leadership style influences on organisational commitment among South African soldiers. Journal of Psychology in Africa, 28(1), 21-25.

Marsden, P. V. (1994). The hiring process: recruitment methods. American Behavioral Scientist, 37(7), 979-991.

Maslow, A. H. (1943). A theory of human motivation. Psychological Review, 50(4), 370.

Mason, C. H., \& Perreault, W. D., Jr. (1991). Collinearity, power, and interpretation of multiple regression analysis. Journal of Marketing Research, 28(3), 268-280.

Mercurio, Z. A. (2015). Affective commitment as a core essence of organizational commitment: An integrative literature review. Human Resource Development Review, 14(4), 389-414.

Messarra, L. (2014). Religious diversity at work: The perceptual effects of religious discrimination on employee engagement and commitment. Contemporary Management Research, 10(1), 59-80.

Messarra, L. C., \& El-Kassar, A. (2010). Effects of religious diversity on the employees' perception and reaction. The Business Review, 15(1), 159-163. http://hdl.handle.net/10725/2363

Meyer, J. P., \& Allen, N. J. (1997). Commitment in the workplace: Theory, research, and application. Sage publications.

Meyer, J. P., \& Herscovitch, L. (2001). Commitment in the workplace: Toward a general model. Human Resource Management Review, 11, 299-326.

Meyer, J., Becker, T., \& Van Dick, R. (2006). Social Identities and Commitments at Work: Toward an Integrative Model. Journal of Organizational Behavior, 27, 665-683.

Morgan, J. (2004). How should business respond to a more religious workplace? SAM Advanced Management Journal, 69(4), 11-19.

Nai, J., Narayanan, J., Hernandez, I., \& Savani, K. (2018). People in more racially diverse neighborhoods are more prosocial. Journal of Personality and Social Psychology, 114(4), 497.

O'Reilly, C. A., Caldwell, D. F., \& Barnett, W. P. (1989). Work group demography, social integration, and turnover. Administrative Science Quarterly, 34, 21-37.

Oskooii, K. A. (2016). How discrimination impacts sociopolitical behavior: A multidimensional perspective. Political Psychology, 37(5), 613-640.

Porter, L. W., \& Steers, R. M. (1973). Organizational, work, and personal factors in employee turnover and absenteeism. Psychological Bulletin, 80(2), 151.

Rangel, E. L., Lyu, H., Haider, A. H., Castillo-Angeles, M., Doherty, G. M., \& Smink, D. S. (2018). Factors associated with residency and career dissatisfaction in childbearing surgical residents. JAMA Surgery, 153(11), 1004-1011.

Ringle, C. M., \& Sarstedt, M. (2016). Gain more insight from your PLS-SEM results. Industrial management \& data systems, 116 (9), 1865-1886.

Riordan, C. M., \& Shore, L. M. (1997). Demographic diversity and employee attitudes: An empirical example of relational demography within work units. Journal of Applied Psychology, 82(3), $342-358$. 
Robalino, D., \& Sayyed, H. (2012). Republic of Lebanon Good Jobs Needed: The Role of Macro, Investment, Education, Labor and Social Protection Policies ("Miles"). Middle East and North Africa Human Development Group (MNSHD).

Rooth, D. O. (2010). Automatic associations and discriminations in hiring: Real world evidence. Labour Economics, 17, 523-534.

Salem, P. (1997). Skirting Democracy: Lebanon's 1996 Elections and Beyond. Middle East Report, 26-29.

Sheldon, M. E. (1971). Investments and involvements as mechanisms producing commitment to organizations. Administrative Science Quarterly, 71(16), 143-150.

Shen, J., Chanda, A., D’Netto, B., \& Monga, M. (2009). Managing diversity through human resource management: An international perspective and conceptual framework. International Journal of Human Resource Management, 20(2), 235-251.

Shmueli, G., Ray, S., Estrada, J. M. V., \& Chatla, S. B. (2016). The elephant in the room: Predictive performance of PLS models. Journal of Business Research, 69(10), 4552-4564.

Shmueli, G., Sarstedt, M., Hair, J. F., Cheah, J. H., Ting, H., Vaithilingam, S., \& Ringle, C. M. (2019). Predictive model assessment in PLS-SEM: guidelines for using PLSpredict. European Journal of Marketing.

Shoobridge, G. E. (2006). Multi-ethnic workforce and business performance: Review and synthesis of the empirical literature. Human Resource Development Review, 5(1), 92-137.

Sullivan, G. M., \& Feinn, R. (2012). Using effect size-or why the P value is not enough. Journal of Graduate Medical Education, 4(3), 279.

Tienari, J., Quack, S., \& Theobald, H. (2002). Organizational Reforms, 'Ideal Workers' and Gender Orders: A Cross-Societal Comparison. Organization Studies, 23(2), 249-279.

Thomas, D. A., \& Ely, R. J. (1996). Making differences matter: A new paradigm for managing diversity. Harvard business review, 74(5), 79-90.
Truong, Y., \& McColl, R. (2011). Intrinsic motivations, self-esteem, and luxury goods consumption. Journal of Retailing and Consumer Services, 18(6), 555-561.

Tsui, A. S. (1990). A multiple-constituency model of effectiveness: An empirical examination at the human resource subunit level. Administrative Science Quarterly, 458-483.

Tsui, A. S., Egan, T. D., \& O'Reilly, C. A., III. (1992). Being different: Relational demography and organizational attachment. Administrative Science Quarterly, 37, 549-579.

Van Knippenberg, D., \& Schippers, M. C. (2007). Work group diversity. Annual Review of Psychology, 58, 515-541.

Van Knippenberg, D., De Dreu, C. K., \& Homan, A. C. (2004). Work group diversity and group performance: an integrative model and research agenda. Journal of Applied Psychology, 89(6), 1008.

Wang, H. J., Chen, X., \& Lu, C. Q. (2020). When career dissatisfaction leads to employee job crafting. Career Development International.

Yousef, D. A. (2000). Organizational commitment: A mediator of the relationships of leadership behavior with job satisfaction and performance in a non-western country. Journal of Managerial Psychology, 15(1), 6-24.

Yu, B. B. (2005). Human resource management practices and affective organizational commitment: A comparison of Chinese employees in a state-owned enterprise and a joint venture. Asia Pacific Journal of Human Resources, 43(3), 332-360.

Zingeser, L. (2004). Career and job satisfaction. The ASHA Leader, 9(20), 4-13.

Publisher's Note Springer Nature remains neutral with regard to jurisdictional claims in published maps and institutional affiliations. 